\title{
Taxonomy needs pluralism, but a controlled and manageable one
}

\author{
ALESSANDRO MINELLI \\ University of Padova, Department of Biology, via Ugo Bassi 58 B, I-35131 Padova, Italy. झ"alessandro.minelli@unipd.it; \\ (1) https://orcid.org/0000-0003-3387-1489
}

\begin{abstract}
What we accept as the units to be classified is not just an expression of our current aims and practices but will also impact further classificatory research. The launch of Megataxa invites a dispassionate discussion about the units to be classified and the names associated to them. Specifically, we must address three challenges.-Challenge 1. Living with pluralism in biological classifications. Despite the enormous amount of ink spent on this issue, there is little hope of finding a species concept at the same time satisfactory from a theoretical point of view and reliable as a guide for taxonomic practice. This unavoidably causes a degree of pluralism in biological classification, as the taxonomic units generally described as species are not necessarily comparable. Also, different users of classification may have different expectations, better satisfied by alternative solutions rather than by a consensus classification. The obvious tension between these different expectations cannot be easily solved by authority or consensus, or simply hoping in the future availability of better criteria for species delimitation. - Challenge 2. Managing multiple classifications within one nomenclature system. Changing taxonomy is the source of ambiguity in the meaning of species names. As a consequence, Linnaean names may not be unique and universal labels for the taxa we recognize. The problem can be solved by specifying taxonomic concepts, i.e. by associating the names to the contexts in which these are used.-Challenge 3. Managing the nomenclature for provisionally circumscribed taxa. Molecular Operational Taxonomic Units (MOTUs) do not correspond necessarily to conventional taxonomic species and no simple or universal rule exists to 'translate' MOTUs into Linnaean species. Provisionally recognized MOTUs do not get a Linnaean name, but are labelled with a formula, in too many cases following no acknowledged standard and thus becoming useless for communication purposes. Non-Linnaean names, or formulas, for provisionally circumscribed taxa cannot be rejected, but some international consensus is needed.
\end{abstract}

Key words: classification, dark taxa, hybridogenetic taxa, megajournal, MOTU, nomenclature, open nomenclature, provisionally circumscribed taxa, species concepts, taxonomic concept

\section{Introduction}

The launch of Megataxa, this ambitious megajournal in taxonomy, invites a dispassionate discussion on some critical issues in our discipline. These issues must be addressed in order to improve current practice both in the production and in the subsequent management and use of taxonomic information. These issues are likely to become even more pressing with the rapid progress in species description to which Megataxa will obviously contribute. Discussing the powerful catalytic effect of megajournals on species description, Zhang (2011) reported that the new taxa described in one year (2010) in one journal (Zootaxa) were in the order of 4000 , an estimated $20 \%$ of all animal taxa described that year. Even larger numbers can be expected for the yearly sets of papers describing at least 100 species required by the editorial policy of Megataxa. A few similarly encompassing papers have been published in recent years, often through the collective effort of numerous researchers (e.g., 100 new lichen species described in Lumbsch et al. 2011), but occasionally also as the work of a single taxonomist (e.g., 101 and 103 new species of the weevil genus Trigonopterus described by Alexander Riedel from New Guinea (Riedel et al. 2013) and Sulawesi (Riedel \& Narakusumo 2019), respectively).

The following discussion will address problems at the level of the units to be classified and the names associated with them. I will not discuss criteria for grouping them into supraspecific taxa, still less the issue of whether supraspecific taxa must be assigned ranks such as genus, family, order etc., as in the Linnaean tradition, or not, as implied by a taxonomy based on phylogenetic principles (e.g., Grifffiths 1974, 1976, de Queiroz 1988, de Queiroz \& Gauthier 1990, Minelli 1991, O'Hara 1993). Examples will be mainly, but not exclusively, from zoology. 


\section{Challenge 1. Living with pluralism in biological} classifications

\section{Is strict consensus in taxonomy possible, or desirable?}

As noted by Wilkins \& Ebach (2013, p. 36), “A natural taxon is some object that is correctly and properly represented by a name, which denotes that object in nature, and is arranged in a natural taxonomy." But a natural taxonomy is not something we discover in nature, it is instead the expression of our worldview: "Over the course of a century or so, a natural classification went from being what we observed without theory to what we derived from theory" (Wilkins \& Ebach 2013, p. 35). Indeed, within the biological community there is a widespread if tacit consensus on the assumption that the units to be classified must be, in some sense, "foundational or fundamental", in other terms, that they must agree with a specified species concept. There are, however, several problems with this assumption.

First, despite the enormous volume of pages hitherto devoted to discussing this issue, there is no consensus solution to the so-called species problem (for a comprehensive discussion of which, see e.g. Coyne \& Orr 2004, Zachos 2016). In particular, there seem to be little hope of finding a species concept at the same time satisfactory from a theoretical point of view and also reliable as a guide in taxonomic practice. A consequence, to which philosophers of biology have paid much more attention than biologists, taxonomists included, is a possible (or necessary?) pluralism in biological classification. Among the positions expressed in the last three decades, some authors (e.g., Kitcher 1984, Ereshefsky 1992, 2001) advocate pluralism, others (e.g., Ghiselin 1987, Hull 1987) reject it. Whenever this problem surfaces, biologists rarely go beyond defending their preferred species notion, e.g., the biological species concept or one of the several varieties of the phylogenetic species concept proposed thus far.

Current progress in taxonomy cannot be halted waiting for an improbable agreement on species concepts. Irrespective of one's personal view on this problem, we must accept that practicing taxonomists will adopt different species concepts, consciously or not. Whatever the cause, this means that all the taxonomic units generally described as species are not necessarily comparable, despite the fact that they are mostly (but far from universally, see below) labelled with Linnaean binomina.

Second, there are good reasons to accept that different users of a classification of living beings may have different expectations that are better satisfied by alternative solutions rather than by aiming at a consensus classification that might express a balanced choice among them. As a consequence, we must address a question that most taxonomists would probably prefer to ignore, that is, if we should better struggle for fighting this latent taxonomic pluralism or, on the contrary, accept it at face value and look for solutions helping us taking best advantage, and risking less danger, from an already present, and possibly growing, pluralism.

In their classic book on plant systematics, Davis \& Heywood (1963) remarked that among living forms there are many kinds of discontinuities, all of which may be of interest. However, as noted e.g. by Mishler \& Donoghue (1982, p. 495), in many instances the sets of organisms delimited by different kinds of discontinuities will not be the same: "If non-correspondence is prevalent, then strict biological species will not necessarily have anything in common but reproductive isolation. It might be argued that a species concept that unambiguously reflects one aspect of variation may be preferable to one that ambiguously reflects several things. But why should we necessarily pin species names on sets of organisms delimited by reproductive barriers? Why not choose, for example, to name morphological units instead?" It is not easy to refute Mishler \& Donoghue's (1982, p. 500) conclusion, that "a variety of species concepts are necessary to adequately capture the complexity of variation patterns in nature. To subsume this variation under the rubric of any one concept leads to confusion and tends to obscure important evolutionary questions," not to mention failing to satisfy the needs of many users of classification. A quite obvious corollary is, that accepting a degree of pluralism in the choice of taxonomic units makes sense only provided that the underlying criteria (e.g., the different species concepts adopted in circumscribing different sets of taxa) are always evident and possibly stated in explicit terms.

Many taxonomists, most of them perhaps, will strongly object to any form of pluralism, but pluralism is already, and solidly, present in current taxonomic practice. For those who need an articulated analysis of the philosophical justification for some degree of pluralism, reading through Conix's (2019) lucid analysis may be profitable. His main point is that the legitimacy of a species classification is determined by a clear decision about the aims of research and how the classification has to be operationally obtained.

Irrespectively of the preference for a given species concept, many taxonomists will agree that "It is not the role of classification to make identification of organisms easy but to reflect the evolutionary history and relationships of organisms as far as we understand it" (Leavitt et al. 2016, p. 488). But many users of the classification will definitely expect that the latter will allow easy allocation of specimens to named species (perhaps, 'species') through diagnostic morphological traits or the availability of easy and cheap molecular markers.

The obvious tension between these opposite 
expectations cannot be easily solved by authority or consensus, or simply hoping in the future availability of better criteria for species delimitation.

I am not proposing here the development of multiple parallel taxonomies. My aim here is to call attention to the fact that for a large number of taxa we cannot hope, at the moment at least, for a universal consensus on a given classification because, in so far as distinct research agendas are pursued and explicitly taken as foundation for the taxonomic work, different legitimate classifications will necessarily result. As the examples in the following section show, this tension is likely to be stronger in groups on which new classificatory efforts have been produced, rather than in those the taxonomy of which is crystallized in a traditional arrangement.

\section{Species taxa based on different species concepts}

Species-level taxa as described by different authors are based on a plurality of species concepts, most often implicity accepted, but sometimes explicitly declared.

"Most biologists agree that discrete clusters exist among sexually reproducing organisms, and behave in their own research as if these groups were real" (Coyne \& Orr 2004, p. 25). This explain the privilege, in delimiting species, often acknowledged as the reproductive isolation (biological species concept, BSC), despite the fact that this condition can actually be demonstrated only in a limited number of instances, and in any case it does not apply to uniparentally reproducing organisms: Ghiselin (1984, p. 213) described uniparentally reproducing organisms as 'like heaps of leaves that have fallen off the tree that gave rise to them' and Mayr (1987) regarded them as worth be recognized as a separate type of taxon-the term 'agamospecies' (Cain 1954) was already available for them.

An idiosyncratic interpretation of the principle of reproductive isolation as a criterion to separate species has been applied by Félix et al. (2014) in a paper in which 15 new species of the nematode genus Caenorhabditis are described. The same group of researchers had previously performed mating tests to establish biological species status among numerous samples of these worms and documented a number of instances of total or partial reproductive isolation among them. Sixteen populations were thus interpreted as representing new species; barcodes based on ITS2 rDNA sequences were obtained for all of them and for a few previously described, closely related species (Kiontke et al. 2011). However, at the time the new species were formally described, these were not diagnosed based on the barcodes (or other molecular or morphological characters), but only based on their reproductive compatibility with other strains. In addition to providing an example of strict priority reserved for reproductive isolation in the circumscription of species, this work is also an example of taxa established on characters only accessible to the authors, who have the privilege to breed in their lab the strains specified as reproductive testers for the specific identity of any additional strain to be studied in the future. An excerpt from Félix et al. (2014, p. 7) will clarify the issue.

Caenorhabditis macrosperma Félix, Braendle \& Cutter sp. nov. urn:lsid:zoobank.org:act:DB7D2F62-D33F-4EDA-B85F0FE780C74A53 = Caenorhabditis sp. 18 [in Kiontke et al . 2011]

The type isolate by present designation is JU1857. The species is delineated and diagnosed by the fertile cross with the type isolate JU1857 in both cross directions, yielding highly fertile hybrid females and males that are interfertile and cross-fertile with their parent strains.

It might be disputed if such a 'diagnosis' fully complies with the requirement of Art. 13.1 of the Code, that "To be available, every new name published after 1930 must [...] be accompanied by a description or a definition that states in words characters that are purported to differentiate the taxon." In the absence of other diagnostic criteria, the formal Linnaean name (Caenorhabditis macrosperma) remains as 'private' as the provisional formula (Caenorhabditis sp. 18).

Of species concepts other than the BSC, the socalled diagnosability version of the Phylogenetic Species Concept (dPSC) has been frequently applied in mammals and birds, especially in clades including emblematic animals targeted by conservation efforts. According to this concept, a species is the least inclusive populationlevel group of organisms with diagnostic traits by which it differs from other such clusters (Cracraft 1983, Wheeler \& Platnick 2000). Application of this species concept has caused a dramatic increase in the number of species recognized in some groups ("taxonomic inflation" in the words of Zachos et al. 2013). The first example was Cracraft's (1992) revision of the birds-of-paradise. Within this group, previous authors, arguably using gaps in morphology as a proxy for reproductive isolation, thus broadly implying adherence to the biological species concept, recognized between 40 and 42 species, many of which polytypic. In his work, Cracraft raised to the species rank 65 subspecies described by previous authors. Combined with other changes, this resulted in counting 90 species in the family, only two of which were actually described by him as new.

More recently, the diagnosability version of the phylogenetic species concept has been applied to several groups of mammals. For example, it has been proposed to recognize three tiger species rather than one, Panthera tigris (Linnaeus, 1758), with acknowledging independent 
species status to the Javan tiger $P$. sondaica (Temminck, 1844) and the Sumatran tiger Panthera sumatrae Pocock, 1929 (Cracraft et al. 1998; Mazak \& Groves 2006). Many more examples are found in Groves \& Gubb's (2011) book on ungulates, including the splitting of the klipspringer Oreotragus oreotragus (Zimmermann, 1783 ) into eleven species. This trend has found favor among a number of mammalogists, e.g. Gippoliti et al. (2013) and Cotterill et al. (2014), but has been strongly opposed by others, e.g. Frankham et al. (2012), Heller et al. (2013), Zachos \& Lovari 2013) and Zachos (2018). In specific cases, however, the proposed splitting is accepted also by mammalogists otherwise very critical of recognizing species taxa according to the dPSC (Zachos et al. 2013): this is the case of the African elephants (the forest elephant Loxodonta cyclotis Matschie, 1900 and the savanna elephant Loxodonta africana (Blumenbach, 1797); cf. Rohland et al. 2010).

In this plurality of species level taxa recognized with reference to different species concepts, a special case is represented by the Least Inclusive Taxonomic Units (LITUs). According to some adherents to phylogenetic nomenclature (Pleijel \& Rouse 1999), these should replace the species as the basic unit of classification. In fact, the difference between a dPSC-diagnosed species and a LITU is mainly one of nomenclature. A LITU could be defined as a dPSC-based unit to which a single-word name (uninominal) has been given instead of a two-word name (binomen) according to the Linnaean tradition. This proposal might be described as a way to constructively react to Mishler's (1999) plea to stop describing species. In practice, however, only a very small number of LITUs have been described (e.g., Pleijel 1999, Pleijel \& Rouse 2000), and this effort seems now to be closed. A LITU described by Pleijel \& Rouse (2000) as capricornia has been recently brought under the discipline of the Code by placing it into a genus, thus becoming Lizardia capricornia (de Araújo Costa et al. 2017).

The prospect of abandoning the species category has been discussed in a balanced way by LaPorte (2007) who concludes that the alternatives to the use of 'species' proposed in connection with conservation efforts or in the context of a rank-free systematics have failed to provide a proper replacement for the species taxon.

\section{Special names for hybridogenetic taxa}

The need to use names (or formulae) departing from the prescriptions of the Code for species-level taxa has been advocated in some specific cases, as for the hybridogenetic green frogs of the genus Pelophylax Fitzinger, 1843. The best known representative of this kind is the socalled edible frog, described by Linnaeus (1758) as Rana esculenta. If we ignore local populations of more complex history and more problematic nature, this frog generally represents a non self-perpetuating hybrid between Pelophylax lessonae (Camerano, 1882) and Pelophylax ridibundus (Pallas, 1771) (Berger 1968, 1983, Dubois 1982, Spolsky \& Uzzell 1986). Gametes produced by the hybrid, however, carry only lessonae or ridibundus genes; therefore, the survival of the hybrid depends on the presence of a syntopic population of the other parental species, the hybrid condition being generated anew at each generation, hence the term hybridogenesis (Schultz 1969) used to describe the phenomenon. To indicate that these hybridogenetic amphibians permanently rely on foreign gametes (i.e., in a sense, they 'steal' gametes from them), it has been proposed to call them kleptons (Dubois \& Günther 1982) rather than species. Their names are obtained by inserting the word 'klepton' between the generic name and the specific epithet. Hybridogenetic frogs are often accepted as species-level taxa (e.g. AmpbibiaWeb 1999) and cited with names such as Pelophylax klepton esculentus (Linnaeus, 1758), but some authors, including some competent amphibian taxonomists, reject them, based on the principle that hybrids, as such, have no separate nomenclatural status in zoology (cf. ICZN 1999, Art. 1.3.3), thus each individual of "Rana esculenta" should simply be described as a hybrid with a genome of Pelophylax lessonae and a genome of Pelophylax ridibundus (Frost 2019).

\section{Challenge 2. Managing multiple classifications within one nomenclature system}

\section{Taxonomic concepts}

As stated in the Preamble to the International Code of Zoological Nomenclature, "The objects of the Code are to promote stability and universality in the scientific names of animals and to ensure that the name of each taxon is unique and distinct". However, universality and stability of nomenclature do not imply that the valid name for a species must remain unchanged forever: it will depend instead on the taxonomic context in which it is embedded, and this context has been changing since Linnaeus, and continues to change to date.

Changing taxonomy is indeed the source of standing ambiguity in the meaning of species names. To use an example first discussed in Minelli (2019), the smallsize populations of the European red deer living in the Mediterranean islands of Sardinia and Corsica (and in North Africa) are generally regarded as taxonomically distinct from the European continental form, but some authorities (e.g., Groves \& Grubb 2011) credit them of distinct species status, while others (e.g., Zachos et al. 2013) regard the distinction as subspecific. As a 
consequence, 'Cervus elaphus' in the sense of Groves \& Grubb (2011), from which the insular and North-African Cervus corsicanus Erxleben, 1777 is excluded, is not the same as 'Cervus elaphus' in the sense of Zachos et al. (2013), which includes C. e. corsicanus (Erxleben, 1777) alongside $C$. e. elaphus Linnaeus, 1758. It cannot be denied that this is an example of taxonomic pluralism - of an accepted, 'legitimate' pluralism. Taxonomic groups for which two or more, conflicting taxonomies coexist are all but rare and a re-visitation of their species diversity from new (molecular, integrative) perspectives often increase, rather than reduce, the conflict.

As a consequence, in the absence of further qualifications, Linnaean names may become semantically instable because of changing taxonomies and thus fail to be the unique and universal labels for taxa prescribed by the Code and needed by all users of nomenclature (Minelli 2019). To be sure, this does not mean that Linnaean taxa and Linnaean nomenclature must be rejected! But we must seriously address the problems that emerge, as soon as we need to aggregate in the same data base, or even simply in a list of synonyms, information from multiple sources that use the same Linnaean name for differently circumscribed taxa. The problem can be solved by paying attention to the context in which a name is used by an author in a particular work, i.e., by specifying taxonomic concepts (Berendsohn 1995), i.e. the precise meanings of names in the different sources and the semantic relationships among them: for example, e.g., "Cervus elaphus Linnaeus (1758) sensu Groves and Gubb (2011)" is part of "Cervus elaphus Linnaeus (1758) sensu Zachos et al. (2013)".

The impact of changing taxonomy on species-level nomenclature has been exhaustively explored in the case of birds. The over 1.5 million taxonomic concepts available in the literature for this group (Lepage et al. 2014), in which ca. 10,000 species and 22,000 subspecies are currently recognized, have been organized in the exemplary database Avibase (Lepage 2019).

\section{Open nomenclature}

Another issue originates from the fundamental distinction between species discovery (with formal description and naming) and the subsequent use of species names when new specimens are identified (Collins \& Cruickshank 2012).

Strictly speaking, scientific nomenclature as ruled by the Codes applies to the names of taxa, but this is not the same as the use of these names by vast majority of users, professional biologists included. Indeed, Art. 1.1 of the zoological Code (ICZN 1999) states that "Zoological nomenclature is the system of scientific names applied to taxonomic units (taxa; singular: taxon) of extant or extinct animals".
This is different from the subsequent use of names as applied to specimens other than the original type material. Very often, even in the case in which there is no reason to presume that a still undescribed taxon is involved, the identification of a specimen with a named species must remain tentative, especially if the material can only be studied morphologically. Think for example of a species in which reliable species-level identification is possible only on characters of the male genitalia, but only females or juveniles are available.

In such cases, the identification of a specimen may remain uncertain even in the hands of a specialist, including the author of the species to which a specimen can be tentatively referred.

To avoid conveying a possibly (or probably) wrong message by using an unflagged Linnaean name, informal and not standardized formats are used (e.g., Lumbricus cf. rubellus). Despite the fact that the relationship between the names of taxa formed according to the rules of the Code and these formulas applied to individual specimens are generally clear, these names depart from pure Linnaean binomina and are thus collectively called open nomenclature (Richter 1948, Matthews 1973, Bengtson 1988, Minelli 2019). A comprehensive analysis of the problem, with suggestions for expressing in a standardized way the different causes and degrees of uncertainty in naming specimens not definitely matching with a named taxon, is provided by Sigovini et al. (2016).

\section{Challenge 3. Managing the nomenclature for provisionally circumscribed taxa}

Popular issues in biodiversity studies relate to the number of species known thus far, and those waiting description. However, the precise figures currently circulating conceal a lot of problems, at least two of which are relevant to the issues discussed in this paper. One of these issues is due to the heterogeneity of taxonomic units bearing a binomial name (discussed above), the other is the fact that the formal description and naming of a large and broadly increasing number of hypothesized new species, the existence of which is reported in the scientific literature, is postponed indefinitely. These hypothesized but undescribed species form a very large part of a set of taxonomic entities known as cryptic species. Of the many (not necessarily congruent) definitions of cryptic species found in the literature (for a list, see Struck et al. 2018), let's follow Bickford et al. (2007), according to whom two or more species deserve be called 'cryptic' if they are currently classified, or have been classified in the past, as a single nominal species because of the apparent lack of morphological distinguishing traits. Morphological differences between molecularly identified species are sometimes missing, 
even in cases in which the divergence between two species has been reconstructed as very old. For example, in the lichen genera Melanelixia and Melanohalea phenotypic differences to be used as diagnostic at the species level may be absent even millions of years after the initial divergence (Leavitt et al. 2012, 2013).

In recent years there has been lively discussion on the nature of cryptic species, their significance for the study of evolution and biodiversity and their possible taxonomic treatment, much less on how to ensure that information about each of them can be publicly shared until a decision is eventually taken about their validity, followed, if this is the case, by formal description and naming. According to Korshunova et al. (2017), the status of cryptic species does not describe a natural phenomenon, but only a temporary problematic formalization of species delineation.

This status of the taxonomy of a group may well be temporary, but the prevalence of the phenomenon is impressive, witness the following picture, based on a survey of 606 publications issued before June 2016, in which cryptic species are mentioned (Struck et al. 2018). Of those papers, less than one in five contains formal descriptions of the hypothesized species, although in some instances (no percentage is given by Struck et al.) a regular taxonomic treatment may have been published in a separate paper. As expected, the vast majority of these papers $(84.2 \%)$ included molecular data but less than one half of them (42.7\%) examined morphological data, alone or combined with molecular information. Three quarters of the papers included an estimate of genetic divergence. Most critically, $35.5 \%$ based cryptic species designation on a single molecular marker, most frequently plastidial or mitochondrial.

The correspondence between the unit taxa delimited according to different criteria is probably intractable if the precise identity of the type material of the species recognized according to a traditional Linnaean classification cannot be determined. In any case, it may require a lot of additional work. Following a study of 414 samples of Xanthoparmelia lichens from western North America, Leavitt et al. (2011) admitted that the genetic clusters inferred from their study based on six nuclear loci cannot be readily aligned with traditional taxonomy. An exhaustive study involving the genetic characterization of the type material of all the Linnaean species potentially involved will hardly be completed soon (if ever), together with the formal description and naming of the hitherto unrecognized taxa deemed worth of recognition, for many of which morphological and chemical diagnostic traits will not be available. Therefore, the authors propose, as a temporary solution, to adopt provisional names for the 21 genetic clusters obtained by a suitable cutting level of their molecular tree. The taxonomic diversity hypothesized by the author was indeed very poorly covered by the named
Linnaean taxa. Only in two instances was there a oneto-one correspondence between Linnaean taxon and molecularly hypothesized lineage ( $X$. mexicana and $X$. stenophylla corresponding to A2 and B3, respectively), more often one Linnaean species corresponded to multiple lineages, in other cases no Linnaean name was available for a lineage. Most disturbing, however, are the instances in which a molecular lineage includes a 'mix' of named and probably also unnamed Linnaean species.

Indeed, taxonomic units inferred from molecular distances, best described as MOTUs (Molecular Operational Taxonomic Units) (Floyd et al. 2002), do not correspond necessarily to conventional taxonomic species, as first stressed by Blaxter et al. (2005) and confirmed by a large number of studies on animal, fungal and plant taxa using a diversity of molecular markers and diversity of species delimitation criteria. Moreover, no simple or universal rule exists to 'translate' MOTUs into Linnaean species and time-consuming and not necessarily exhaustive effort is necessary to place in the standard Linnaean classification the MOTUs that eventually deserve to be acknowledged as species, nevertheless this should be regarded as a necessary effort (Trontelj \& Fišer 2009; Pérez-Ponce de León \& Nadler 2010; Minelli 2017b).

The fact that provisionally recognized MOTUs do not get a Linnaean name, but are simply labelled with a formula, is not a problem per se, but in too many cases the formulas found in papers and data bases are useless for communication purposes. The real problem (critically discussed by Schindel \& Miller 2010, Pante et al. 2015, Morard et al. 2016, Minelli 2017a, 2019) is that it is generally impossible to trace these formulas from a paper to another or from a database to another. In the absence of a sentence specifying that the taxon provisionally called 'Lumbricus sp. A' in a given paper is the same as the 'Lumbricus sp. A' mentioned in another paper, even among the papers of the same author(s), there is no reason to expect that the identical formula will actually refer to an identical taxon. These provisionally labelled 'dark taxa' (to use a term informally introduced by Roderick Page, http://iphylo.blogspot.com/2011/04/dark-taxa-genbankin-post-taxonomic.html) thus remain unrecognizable and as much as useless (Samyn \& De Clerck 2012, Ryberg \& Nilsson 2018).

The problem, however, is not due to the fact that these formulas do not comply with the rules of the Codes, but to the lack of the standardization required for effective communication. Non-Linnaean names, or formulas, for provisionally circumscribed taxa (somehow comparable to the candidatus status in bacteriology) require international agreement on a few point points (cf. Schindel \& Miller 2010, Morard et al. 2016, Minelli 2017a, 2019), the most important of which are the requirements that each non 
Code-compliant name or formula remains permanently associated with source information (author and year for the names or formulas introduced in a publication, and equivalent information, in a format to be specified, for those first used as database entries) and material vouchers are preserved and retrievable.

\section{Conclusions}

Standardization of practice must not be pushed so far, that useful information is lost. This implies that we live with some degree of pluralism, both in the list of taxa we recognize, and the names we use for them. However, this will work only in so far as we complement the Code with internationally agreed provisions for handling both the names for taxonomic units that cannot be correctly handled under the Codes and the plurality of taxonomic concepts that are associated with the same Linnaean names. These needs are likely to increase, rather than disappear, with the forthcoming advances in taxonomy. The earlier we recognize these problems and adopt viable solutions, the better for taxonomy as well as for the users of classifications and names of taxa.

While managing current practice, we must also be aware that any choice about what we accept as the units to be classified is just an expression of our current aims and practices. Whichever the choice, it will also impact on further classificatory research (Conix 2019).

\section{Acknowledgements}

I am grateful to Zhi-Qiang Zhang for kindly inviting me to discuss a set of critical issues in taxonomy, at the time of the launch of Megataxa: many thanks and the best wishes for a new worldwide success with the new journal!

\section{References}

AmphibiaWeb (1999) Pelophylax esculentus: Edible Frog. University of California, Berkeley, CA, USA. Available from: http://amphibiaweb.org/species/5029 (Accessed Nov 24, 2019)

Bengtson, P. (1988) Open nomenclature. Palaeontology, 31 (1), 223-227.

Berendsohn, W.G. (1995) The concept of "potential taxa" in databases. Taxon, 44 (2), 207-212. https://doi.org/10.2307/1222443

Berger, L. (1968) Morphology of the F1 generation of various crosses within Rana esculenta-complex. Acta Zoologica Cracoviensia, 13, 301-324.

Berger, L. (1983) Western Palearctic water frogs (Amphibia, Ranidae): systematics, genetics and population compositions. Experientia, 39, 127-130.
https://doi.org/10.1007/BF01958859

Bickford, D., Lohman, D.J., Sodhi, N.S., Ng, P.K.L., Meier, R., Winker, K., Ingram, K.K. \& Das, I. (2007) Cryptic species as a window on diversity and conservation. Trends in Ecology \& Evolution, 22 (3), 148-155.

https://doi.org/10.1016/j.tree.2006.11.004

Blaxter, M., Mann, J., Chapman, T., Thomas, F., Whitton, C., Robin Floyd, R. \& Abebe, E. (2005) Defining operational taxonomic units using DNA barcode data. Philosophical Transactions of the Royal Society of London B Biological Sciences, 360, 1935-1943.

https://doi.org/10.1098/rstb.2005.1725

Cain, A.J. (1954) Animal Species and Their Evolution. Hutchinson University Library, London, ix+11-190 pp.

Collins, R.A. \& Cruickshank, R.H. (2012) The seven deadly sins of DNA barcoding. Molecular Ecology Resources, 13 (6), 969975. https://doi.org/10.1111/1755-0998.12046

Conix, S. (2019) Radical pluralism, classificatory norms and the legitimacy of species classifications. Studies in History and Philosophy of Biological and Biomedical Sciences, 73, 2734.

https://doi.org/10.1016/j.shpsc.2018.11.002

Cotterill, F.P.D., Taylor, P.J., Gippoliti, S., Bishop, J.M. \& Groves, C.P. (2014) Why one century of phenetics is enough: response to 'Are there really twice as many bovid species as we thought?'. Systematic Biology, 63 (5), 819-832.

https://doi.org/10.1093/sysbio/syu003

Coyne, J.A. \& Orr, H.A. (2004) Speciation. Sinauer Associates, Sunderland, MA, xiii $+545 \mathrm{pp}$.

Cracraft, J. (1992) The species of the birds-of-paradise (Paradisaeidae): Applying the phylogenetic species concept to a complex pattern of diversification. Cladistics, 8 (1), 1-43. https://doi.org/10.1111/j.1096-0031.1992.tb00049.x

Cracraft, J. (1983) Species concepts and speciation analysis. In: Johnston, R.F. (Ed.) Current Ornithology, 1. Plenum, New York, pp. 159-187.

https://doi.org/10.1007/978-1-4615-6781-3_6

Cracraft, J., Feinstein, J., Vaughn, J. \& Helm-Bychowski, K. (1998) Sorting out tigers (Panthera tigris): mitochondrial sequences, nuclear inserts, systematics, and conservation genetics. Animal Conservation, 1 (2), 139-150. https://doi.org/10.1111/j.1469-1795.1998.tb00021.x

Davis, P.H. \& Heywood, V.H. (1963) Principles of angiosperm taxonomy. Oliver and Boyd, Edinburgh, $\mathrm{xx}+556 \mathrm{pp}$.

de Araújo Costa, D., de Assis da Silva, F., Christoffersen, M.L. \& Furtado, G.D. (2017) Lizardia capricornia new status (Polychaeta, Hesionidae), including morphological data and biogeographic notes. Revista de Ciências da Saúde Nova Esperança, 15 (2), 5-10. https://doi.org/10.17695/issn.2317-7160.v15n2a2017p5-10

de Queiroz, K. \& Gauthier, J. (1990) Phylogeny as a central principle in taxonomy: Phylogenetic definitions of taxon names. Systematic Zoology, 39 (4), 307-322. https://doi.org/10.2307/2992353

de Queiroz, K. (1988) Systematics and the Darwinian revolution. Philosophy of Science, 55 (2), 238-259. https://doi.org/10.1086/289430

Donoghue, M.J. \& Gauthier, J.A. (2004) Implementing the PhyloCode. Trends in Ecology \& Evolution, 19 (6), 281-282. https://doi.org/10.1016/j.tree.2004.04.004

Dubois, A. \& Günther, R. (1982) Klepton and synklepton: Two new evolutionary systematics categories in zoology. Zoologische 
Jahrbücher. Abteilung für Systematik, Ökologie und Geographie, 109, 290-305.

Dubois, A. (1982) Notes sur les grenouilles vertes (groupe de Rana k1. esculenta Linné, 1758) I. Introduction. Alytes, 1, 42-49.

Ereshefsky, M. (1992) Eliminative pluralism. Philosophy of Science, 59 (4), 671-690. https://doi.org/10.1086/289701

Ereshefsky, M. (2001) The poverty of the linnaean hierarchy: A philosophical study of biological taxonomy. Cambridge University Press, Cambridge, $\mathrm{x}+316 \mathrm{pp}$. https://doi.org/10.1017/CBO9780511498459

Félix, M.-A., Braendle, C. \& Cutter, A.D. (2014) A streamlined system for species diagnosis in Caenorhabditis (Nematoda: Rhabditidae) with name designations for 15 distinct biological species. PLoS ONE, 9 (4), e94723. https://doi.org/10.1371/journal.pone.0094723

Floyd, R., Eyualem, A., Papert, A. \& Blaxter, M. (2002) Molecular barcodes for soil nematode identification. Molecular Ecology, 11 (4), 839-850. https://doi.org/10.1046/j.1365-294X.2002.01485.x

Frankham, R., Ballou, J.D., Dudash, M.R., Eldridge, M.D.B., Fenster, C.B., Lacy, R.C., Mendelson J.R. III, Porton, I.J., Ralls, K. \& Ryder, O.A. (2012) Implications of different species concepts for conserving biodiversity. Biological Conservation, 153, 25-31. https://doi.org/10.1016/j.biocon.2012.04.034

Frost, D.R. (2019) Amphibian species of the world: an online reference. Version 6.0. American Museum of Natural History, New York. http://research.amnh.org/herpetology/amphibia/ index.html (Accessed 24 Nov. 2019)

Ghiselin, M.T. (1984) Narrow approaches to phylogeny: A review of nine books on cladism. In: Dawkins, R. \& Ridley, M. (Eds.), Oxford Surveys in Evolutionary Biology, Vol. 1. Oxford University Press, Oxford, pp. 209-222.

Ghiselin, M.T. (1987) Species concepts, individuality, and objectivity. Biology \& Philosophy, 2 (2), 127-143. https://doi.org/10.1007/BF00057958

Gippoliti, S., Cotterill, F.P.D. \& Groves, C. (2013) Mammal taxonomy without taxonomists: a reply to Zachos and Lovari. Hystrix, 24, 3-5.

https://doi:10.4404/hystrix-24.1-8881

Griffiths, G.C.D. (1974) On the foundations of biological systematics. Acta Biotheoretica, 23, 85-131. https://doi.org/10.1007/BF01556343

Griffiths, G.C.D. (1976) The future of Linnaean nomenclature. Systematic Zoology, 25 (2), 168-173. https://doi.org/10.2307/2412743

Groves, C. \& Grubb, P. (2011) Ungulate Taxonomy. The Johns Hopkins University Press, Baltimore, ix +317 pp.

Heller, R., Frandsen, P., Lorenzen, E.D. \& Siegismund, H.R. (2013) Are there really twice as many bovid species as we thought? Systematic Biology, 62 (5), 490-493. https://doi.org/10.1093/sysbio/syt033

Hull, D.L. (1987) Genealogical actors in ecological roles. Biology \& Philosophy, 2 (2), 168-184. https://doi.org/10.1007/BF00057961

International Commission on Zoological Nomenclature (1999) International Code of Zoological Nomenclature (4th ed.). The International Trust for Zoological Nomenclature, London, $\mathrm{xxix}+271 \mathrm{pp}$.

Kiontke, K.C., Félix, M.-A., Ailion, M., Rockman, M.V., Braendle, C., Pénigault, J.-B. \& Fitch, D.H.A. (2011) A phylogeny and molecular barcodes for Caenorhabditis, with numerous new species from rotting fruits. BMC Evolutionary Biology, 11, 339.

https://doi.org/10.1186/1471-2148-11-339

Kitcher, P. (1984) Species. Philosophy of Science, 51 (2), 308333.

https://doi.org/10.1086/289182

Korshunova, T., Martynov, A., Bakken, T. \& Picton, B. (2017) External diversity is restrained by internal conservatism: new nudibranch mollusc contributes to the cryptic species problem. Zoologica Scripta, 46 (6), 683-692. https://doi.org/10.1111/zsc. 12253

LaPorte, J. (2007) In defense of species. Studies in History and Philosophy of Biological and Biomedical Sciences, 38 (1), 255-269. https://doi.org/10.1016/j.shpsc.2006.12.013

Leavitt, S.D., Divakar, P.K, Crespo, A. \& Lumbsch, H.T. (2016) A matter of time - understanding the limits of the power of molecular data for delimiting species boundaries. Herzogia, 29 (2), 479-492.

https://doi.org/10.13158/heia.29.2.2016.479

Leavitt, S.D., Esslinger, T.L., Divakar, P.K. \& Lumbsch, H.T. (2012) Miocene divergence, phenotypically cryptic lineages, and contrasting distribution patterns in common lichen-forming fungi (Ascomycota: Parmeliaceae). Biological Journal of the Linnean Society, 107 (4), 920-937.

https://doi.org/10.1111/j.1095-8312.2012.01978.x

Leavitt, S.D., Esslinger, T.L., Spribille, T., Divakar, P.K. \& Lumbsch, H.T. (2013) Multilocus phylogeny of the lichen-forming fungal genus Melanohalea (Parmeliaceae, Ascomycota): Insights on diversity, distributions, and a comparison of species tree and concatenated topologies. Molecular Phylogenetics and Evolution, 66 (1), 138-152.

https://doi.org/10.1016/j.ympev.2012.09.013

Leavitt, S.D., Johnson L.A., Goward T. \& St. Clair L.L. (2011) Species delimitation in taxonomically difficult lichenforming fungi: an example from morphologically and chemically diverse Xanthoparmelia (Parmeliaceae) in North America. Molecular Phylogenetics and Evolution, 60(3), 317-332. https://doi.org/10.1016/j.ympev.2011.05.012

Lepage, D. (2019) Avibase-the World Bird Database. http://aviba se.bsc-eoc.org (Accessed July 30, 2019).

Lepage, D., Vaidya, G. \& Guralnick, R. (2014) Avibase-A database system for managing and organizing taxonomic concepts. ZooKeys, 420, 117-135.

https://doi.org/10.3897/zookeys.420.7089

Linnaeus, C. (1758) Systema naturce per regna tria naturce, secundum classes, ordines, genera, species, cum characteribus, differentiis, synonymis, locis, Editio X. 1. Laurentius Salvius, Stockholm, [II]+683+[1] pp.

https://doi.org/10.5962/bhl.title.542

Lumbsch, H.T., Ahti, T., Altermann, S., De Paz, G.A., Aptroot, A., Arup, U., Pena, A.B., Bawingan, P.A., Benatti, M.N., Betancourt, L., Bjork, C.R., Boonpragob, K., Brand, M., Bungartz, F., Caceres, M.E.S., Candan, M., Chaves, J.L., Clerc, P., Common, R., Coppins, B.J., Crespo, A., DalForno, M., Divakar, P.K., Duya, M.V., Elix, J.A., Elvebakk, A., Fankhauser, J.D., Farkas, E., Ferraro, L.I., Fischer, E., Galloway, D.J., Gaya, E., Giralt, M., Goward, T., Grube, M., Hafellner, J., Hernandez, J.E., Campos, M.D.H., Kalb, K., Karnefelt, I., Kantvilas, G., Killmann, D., Kirika, P., Knudsen, K., Komposch, H., Kondratyuk, S., Lawrey, J.D., Mangold, A., Marcelli, M.P., Mccune, B., Messuti, M.I., Michlig, A., Gonzalez, R.M., Moncada, B., Naikatini, A., Nelsen, M.P., 
Ovstedal, D.O., Palice, Z., Papong, K., Parnmen, S., PerezOrtega, S., Printzen, C., Rico, V.J., Plata, E.R., Robayo, J., Rosabal, D., Ruprecht, U., Allen, N.S., Sancho, L., De_Jesus, L.S., Vieira, T.S., Schultz, M., Seaward, M.R.D., Serusiaux, E., Schmitt, I., Sipman, H.J.M., Sohrabi, M., Sochting, U., Sogaard, M.Z., Sparrius, L.B., Spielmann, A., Spribille, T., Sutjaritturakan, J., Thammathaworn, A., Thell, A., Thor, G., Thus, H., Timdal, E., Truong, C., Turk, R., Tenorio, L.U., Upreti, D.K., Van den Boom, P., Rebuelta, M.V., Wedin, M., Will-Wolf, S., Wirth, V., Wirtz, N., Yahr, R., Yeshitela, K., Ziemmeck, F., Wheeler, T. \& Lucking R. (2011) One hundred new species of lichenized fungi: a signature of undiscovered global diversity. Phytotaxa, 18, 1-127.

https://doi.org/10.11646/phytotaxa.18.1.1

Matthews, S.C. (1973) Notes on open nomenclature and on synonymy lists. Palaeontology, 16 (4), 713-719.

Mayr, E. (1987) The ontological status of species: Scientific progress and philosophical terminology. Biology \& Philosophy, 2 (2), 145-166. https://doi.org/10.1007/BF00057959

Mazak J.H. \& Groves, C.P. (2006) A taxonomic revision of tigers (Panthera tigris) of Southeast Asia. Mammalian Biology, 71 (5), 268-287. https://doi.org/10.1016/j.mambio.2006.02.007

Minelli, A. (1991) Names for the system and names for the classification. In: Hawksworth, D.L. (Ed.) Improving the stability of names: Needs and options (Regnum Vegetabile No. 123), Koeltz, Konigstein, pp. 183-189.

Minelli, A. (2017a) Grey nomenclature needs rules. Ecologica Montenegrina, 7, 656-666.

Minelli, A. (2017b) Updating taxonomic practice to cope with challenges from within and without the discipline. Biodiversity Journal, 8(1), 671-674.

Minelli, A. (2019) The galaxy of the non-Linnaean nomenclature. History and Philosophy of the Life Sciences, 41, 31. https://doi.org/10.1007/s40656-019-0271-0

Mishler, B. (1999) Getting rid of species? In: Wilson, R.A. (Ed.) Species: New interdisciplinary essays. MIT Press, Cambridge, MA, pp. 307-315.

Mishler, B., \& Donoghue, M. (1982) Species concepts: A case for pluralism. Systematic Zoology, 31 (4), 491-503. https://doi.org/10.1093/sysbio/31.4.491

Morard, R., Escarguel, G., Weiner, A.K., André, A., Douady, C.J., Wade, C.M., Darling, K.F., Ujiié, Y., Seears, H.A., Quillévéré, F., de Garidel-Thoron, T., de Vargas, C. \& Kucera, M. (2016) Nomenclature for the nameless: A proposal for an integrative molecular taxonomy of cryptic diversity exemplified by planktonic Foraminifera. Systematic Biology, 65 (5), 925940.

https://doi.org/10.1093/sysbio/syw031

O'Hara, R. (1993) Systematic generalization, historical fate, and the species problem. Systematic Biology, 42 (3), 231-246. https://doi.org/10.1093/sysbio/42.3.231

Pante, E., Schoelinck, C. \& Puillandre, N. (2015) From integrative taxonomy to species description: one step beyond. Systematic Biology, 64 (1), 152-160.

https://doi.org/10.1093/sysbio/syu083

Pérez-Ponce de León, G. \& Nadler, S.A. (2010) What we don’t recognize can hurt us: A plea for awareness about cryptic species. Journal of Parasitology, 96, 453-464. https://doi.org/10.1645/GE-2260.1

Pleijel, F. \& Rouse, G.W. (1999) Least-inclusive taxonomic unit: a new taxonomic concept for biology. Proceedings of the Royal
Society of London B, 267, 627-630.

https://doi.org/10.1098/rspb.2000.1048

Pleijel, F. \& Rouse, G.W. (2000) A new taxon, capricornia (Hesionidae, Polychaeta), illustrating the LITU ('leastinclusive taxonomic unit') concept. Zoologica Scripta, 29, 157-168. https://doi.org/10.1046/j.1463-6409.2000.00041.x

Pleijel, F. (1999) Phylogenetic taxonomy, a farewell to species, and a revision of Heteropodarke (Hesionidae, Polychaeta, Annelida). Systematic Biology, 48 (4), 755-789. https://doi.org/10.1080/106351599260003

Richter, R. (1948) Einführung in die Zoologische Nomenklatur durch Erläuterung der Internationalen Regeln. 2nd ed. Waldemar Kramer. Frankfurt, 252 pp.

Riedel A., Sagata K., Surbatki S., Tänzler R. \& Balke M. (2013) One hundred and one new species of Trigonopterus weevils from New Guinea. ZooKeys, 280, 1-150. https://doi.org/10.3897/zookeys.280.3906

Riedel, A. \& Narakusumo, R.P. (2019) One hundred and three new species of Trigonopterus weevils from Sulawesi. ZooKeys, $828,1-153$. https://doi.org/10.3897/zookeys.828.32200

Rieppel, O. (2010) Species monophyly. Journal of Zoological Systematics and Evolutionary Research, 48, 1-8. https://doi.org/10.1111/j.1439-0469.2009.00545.x

Rohland, N., Reich, D., Mallick, S., Meyer, M., Green, R.E., Georgiadis, N.J., Roca, A.L. \& Hofreiter, M. (2010) Genomic DNA sequences from mastodon and woolly mammoth reveal deep speciation of forest and savanna elephants. PLoS Biology, 8 (12), e1000564. https://doi.org/10.1371/journal.pbio.1000564

Samyn, Y. \& De Clerck, O. (2012) No name, no game. European Journal of Taxonomy, 10, 1-3. https://doi.org/10.5852/ejt.2012.10

Schindel, D.E. \& Miller, S.E. (2010) Provisional nomenclature: The on-ramp to taxonomic names. In: Polaszek, A. (Ed.), Systema naturae 250: The Linnaean Ark. CRC, Boca Raton, pp. 109-115. https://doi.org/10.1201/EBK1420095012-c10

Schultz, R.J. (1969) Hybridization, unisexuality and polyploidy in the teleost Poeciliopsis (Poecilidae) and other vertebrates. American Naturalist, 108 (934), 605-619. https://doi.org/10.1086/282629

Sigovini, M., Keppel, E. \& Tagliapietra, D. (2016) Open nomenclature in the biodiversity era. Methods in Ecology and Evolution, 7 (10), 1217-1225. https://doi.org/10.1111/2041-210X.12594

Spolsky, C.M. \& Uzzell, T. (1986) Evolutionary history of the hybridogenetic hybrid frog Rana esculenta as deduced from mtDNA analyses. Molecular Biology and Evolution, 3 (1), 44-56. https://doi.org/10.1093/oxfordjournals.molbev.a040376

Struck, T.H., Feder, J.L., Bendiksby, M., Birkeland, S., Cerca, J., Gusarov, V.I., Kistenich, S., Larsson, K.-H.H., Liow, L.H., Nowak, M.D., Stedje, B., Bachmann, L. \& Dimitrov, D. (2018) Finding evolutionary processes hidden in cryptic species. Trends in Ecology \& Evolution, 33 (3), 153-163. https://doi.org/10.1016/j.tree.2017.11.007

Trontelj, P. \& Fišer, C. (2009) Cryptic species diversity should not be trivialized. Systematics and Biodiversity, 7 (1), 1-3. https://doi.org/10.1017/S1477200008002909

Wheeler, Q.D. \& Platnick, N.I. (2000) The phylogenetic species concept (sensu Wheeler and Platnick). In: Wheeler, Q.D. \& 
Meier, R. (Eds.) Species concepts and phylogenetic theory - a debate. Columbia University Press, New York, pp. 55-69.

Wilkins, J.S. \& Ebach, M.C. (2013) The nature of classification: relationships and kinds in the natural sciences. Palgrave Macmillan, Basingstoke, $\mathrm{x}+197 \mathrm{pp}$.

Zachos, F.E. \& Lovari, S. (2013) Taxonomic inflation and the poverty of the Phylogenetic Species Concept - a reply to Gippoliti and Groves. Hystrix, 24 (2), 142-144. https://doi.org/10.4404/hystrix-24.1-8849

Zachos, F.E. (2016) Species concepts in biology. Historical development, theoretical foundations and practical relevance. Springer International Publishing, Cham, xii +220 pp.

Zachos, F.E. (2018) Mammals and meaningful taxonomic units: the debate about species concepts and conservation. Mammal
Review, 48 (3), 153-159.

https://doi.org/10.1111/mam.12121

Zachos, F.E., Apollonio, M., Barmann, E.V., Festa-Bianchet, M., Göhlich, U., Habel , J.C., Haring, E., Kruckenhauser, L., Lovari, S., McDevitt, A.D., Pertoldi, C., Rössner, G.E., Sánchez-Villagra, M.R., Scandura, M. \& Suchentrunk, F. (2013) Species inflation and taxonomic artefacts. A critical comment on recent trends in mammalian classification. Mammalian Biology, 78 (1), 1-6.

https://doi.org/10.1016/j.mambio.2012.07.083

Zhang, Z.-Q. (2011) Accelerating biodiversity descriptions and transforming taxonomic publishing: the first decade of Zootaxa. Zootaxa, 2896, 1-7.

https://doi.org/10.11646/zootaxa.2896.1.1 